\title{
Molecular evidence for natural hybridization between wild loquat (Eriobotrya japonica) and its relative $E$. prinoides
}

Qiang Fan ${ }^{1 \dagger}$, Sufang Chen ${ }^{1+}$, Mingwan $\mathrm{Li}^{1}$, Wei Guo ${ }^{2}$, Huijuan Jing ${ }^{1}$, Wei Wu ${ }^{3}$, Renchao Zhou ${ }^{1 *}$ and Wenbo Liao ${ }^{{ }^{*}}$

\begin{abstract}
Background: Interspecific hybridization has long been recognized as a pivotal process in plant evolution and speciation. It occurs fairly common in the genera of the subtribe Pyrinae. In Eriobotrya, a small tree genus of Pyrinae, E. prinoides var. daduheensis has been recognized as either a variety of E. prinoides, a natural hybrid between E. prinoides and E. japonica, or a variety of E. japonica. However, to date, there has been no convincing evidence on its status.
\end{abstract}

Results: Four nuclear genes and two chloroplast regions were sequenced in 89 individuals of these three Eriobotrya taxa from two locations where they coexist. A few fixed nucleotide substitutions or gaps were found in each of the investigated nuclear and chloroplast loci between E. japonica and E. prinoides. Of the 35 individuals of E. prinoides var. daduheensis, 33 showed nucleotide additivity of E. japonica and E. prinoides in at least one nuclear gene, and 10 of them harboured nucleotide additivity at all the four nuclear genes. Most haplotypes of E. prinoides var. daduheensis were also shared with those of E. japonica and E. prinoides. In the two chloroplast regions, 28 and 7 individuals were identical with E. japonica and E. prinoides, respectively.

Conclusions: Our study provides compelling evidence for a hybrid status for E. prinoides var. daduheensis. Most hybrid individuals are later-generation hybrids. Both E. japonica and E. prinoides can serve as female parent. Differential adaptation might maintain the species boundary of $E$. prinoides and E. japonica in the face of hybridization and potential introgression.

Keywords: Eriobotrya, Hybridization, Nuclear genes, Chloroplast DNA

\section{Background}

Interspecific hybridization has long been recognized as a pivotal process in plant evolution and speciation [1-3]. The understanding of the process of natural hybridization could not only help to clarify taxonomic uncertainty, but also contribute to illuminate the origin of many adaptations, the maintenance of plant diversity and the process of speciation [2]. Natural hybridization occurs fairly commonly among and within genera of the subtribe Pyrinae (formerly the Maloideae, Rosaceae), which contains many

\footnotetext{
* Correspondence: zhrench@mail.sysu.edu.cn; Isslwb@mail.sysu.edu.cn ${ }^{\dagger}$ Equal contributors

'Guangdong Key Laboratory of Plant Resources, Key Laboratory of Biodiversity Dynamics and Conservation of Guangdong Higher Education Institutes, School of Life Sciences, Sun Yat-sen University, Guangzhou 510275, China

Full list of author information is available at the end of the article
}

economically important fruits, such as apple, pawpaw, pear and loquat [4]. Intergeneric hybridization has been observed in 16 genera of Pyrinae [5], while intrageneric hybridization is expected to be even more frequent and has been found in many genera of Pyrinae, including Amelanchier [6], Crataegus [7-9], and Sorbus [10,11]. The prevalence of natural hybridization among and within the genera of Pyrinae indicates that hybridization may play important roles in the evolution of Pyrinae [4], and provides enormous opportunities to breed new cultivars of fruits.

The genus Eriobotrya Lindl., a small genus of Pyrinae consisting of approximately 26 species, is distributed in Himalaya, eastern Asia and western Malesia [12]. Eriobotrya japonica (Thunb.) Lindl., commonly known as loquat, is an important fruit tree cultivated throughout Southeastern Asia [13,14], while wild loquat is only 
distributed in Yunnan, Sichuan, Hubei, Guangxi and Guangdong of China [15]. Of the 21 Eriobotrya species found in China, there are three Eriobotrya species flowering in autumn except for loquat, including $E$. prinoides, E. prinoides var. daduheensis and E. malipoensis: E. prinoides Rehd. et Wils. occurs naturally in Sichuan and Yunnan, E. prinoides var. daduheensis H. Z. Zhang is distributed in two counties of Sichuan, Hanyuan and Shimian, while E. malipoensis occurs only in Malipo, Yunnan [15].

E. prinoides var. daduheensis has many intermediate morphological characteristics of E. japonica and E. prinoides as well as a unique pollen shape and peroxidase isozyme pattern [16]. It was later considered to be an interspecific hybrid between E. japonica and E. prinoides based on karyotype and peroxidase isozyme data [17]. In that study, all three taxa were reported as diploids with identical chromosomes $(2 \mathrm{n}=2 \mathrm{x}=34)$. Additionally, the karyotype of E. prinoides var. daduheensis was either the 3A type (identical with E. japonica) or the 2A type (identical with E. prinoides), and E. prinoides var. daduheensis displayed some additivity in the peroxidase allozyme between E. japonica and E. prinoides. Further karyotype analysis by Liang et al. obtained different results in which all three taxa were the 2A type. Thus, they reconsidered E. prinoides var. daduheensis as a distinct variety of E. japonica [18].

These controversial results were based mostly on conventional approaches such as morphological analysis, karyotype and allozyme assay, which are far enough to provide convincing conclusions for many species showing a high degree of morphological plasticity or intermediate morphological characters arising from forces other than hybridization [19]. For most species in the subtribe Pyrinae, the frequent occurrence of polyploidization, apomixis and hybridization makes identification of hybridization events even more difficult based on these conventional approaches.

Recently, single or low-copy nuclear genes have been used successfully for identifying hybridization in plants [19-21]. The completion of the apple genome sequence provides ample ESTs for the development of exon-primed and intron-crossing (EPIC) primers to detect DNA sequence variations in the members of the subtribe Pyrinae [22-24]. In this study, more than 20 individuals of each of the three taxa (E. prinoides var. daduheensis, E. japonica and E. prinoides) were sampled from two locations (Hanyuan and Shimian), and four low-copy nuclear genes and two chloroplast DNA fragments were sequenced to address the following two questions: 1) Is E. prinoides var. daduheensis an interspecific hybrid? 2) If so, what is the extent of hybridization? Are these hybrid individuals $\mathrm{F}_{1} \mathrm{~s}$ or later generation hybrids, or both? Through these efforts, we further discussed factors that may contribute to the occurrence of hybridization, the effect of hybridization on their parent species, and the possible mechanism of species integrity in the face of gene flow.

\section{Results}

At these four nuclear genes and two chloroplast regions, E. japonica and E. prinoides showed fixed nucleotide substitutions. There were two fixed nucleotide substitutions at TPP2, five nucleotide substitutions and one 1-bp indel at GDSL1, four nucleotide substitutions at GDSL2, three nucleotide substitutions and one 90-bp indel at WD, and three nucleotide substitutions in the $r b c \mathrm{~L}+$ psbB region (Table 1; Figure 1 ).

We next focused on the sites that exhibited fixed differences between E. japonica and E. prinoides for sequence analysis in E. prinoides var. daduheensis. For convenience, we designated the sequence type for each individual of E. prinoides var. daduheensis as $\mathrm{H}$, J and $\mathrm{P}$ types if its sequence chromatogram was additive of E. japonica and E. prinoides, identical with E. japonica, and identical with E. prinoides, respectively. Of the 35 individuals of E. prinoides var. daduheensis, 33 showed nucleotide additivity of E. japonica and $E$. prinoides ( $\mathrm{H}$ type) in at least at one nuclear gene (Table 2 ).

Among the 35 individuals of E. prinoides var. daduheensis, ten individuals were observed with $\mathrm{H}$ type at all four nuclear genes and 23 individuals harbored $\mathrm{H}$ type in at least one nuclear gene (Table 2). For the remaining two individuals, one (DP6) was P type at all four nuclear genes, and the other (DP8) was either P type or J type at the four nuclear genes. Nine of the 21 individuals with typical E. prinoides var. daduheensis characteristics (D1-D21) were observed with a $\mathrm{H}$ type at all four nuclear genes, while only one individual exhibited a $\mathrm{H}$ type at all four nuclear genes for those atypical individuals of E. prinoides var. daduheensis (DP1-DP9 and DJ1-DJ5: morphologically intermediate between $E$. prinoides var. daduheensis and either E. prinoides or E. japonica). At these nuclear genes, only two of these atypical individuals had a J type in two nuclear genes (Table 2).

Table 1 Fixed nucleotide substitutions and gaps between $E$. japonica and $E$. prinoides in the four nuclear genes (TPP2, GDSL1, GDSL2 and WD) and the two chloroplast genes (psbB and rbcL)

\begin{tabular}{lllllllllll}
\hline Gene & \multicolumn{1}{c}{ GDSL1 } & \multicolumn{1}{c}{ GDSL2 } \\
\hline Site & 21 & 229 & 243 & 292 & 293 & 595 & 216 & 238 & 264 & 562 \\
E. japonica & A & A & G & G & - & A & T & C & C & A \\
E. prinoides & G & C & T & A & A & T & G & G & G & T \\
Gene & TPP2 & WD & & & & & psbB & rbcL \\
Site & 36 & 117 & 35 & $270-359$ & 365 & 505 & 91 & 101 & 154 \\
E. japonica & $\mathrm{C}$ & $\mathrm{C}$ & $\mathrm{T}$ & - & & $\mathrm{G}$ & $\mathrm{A}$ & $\mathrm{G}$ & $\mathrm{C}$ & $\mathrm{T}$ \\
E. prinoides & $\mathrm{T}$ & $\mathrm{T}$ & $\mathrm{G}$ & $\mathrm{ACA} . .$. & $\mathrm{C}$ & $\mathrm{T}$ & $\mathrm{A}$ & $\mathrm{A}$ & $\mathrm{G}$ \\
\hline
\end{tabular}




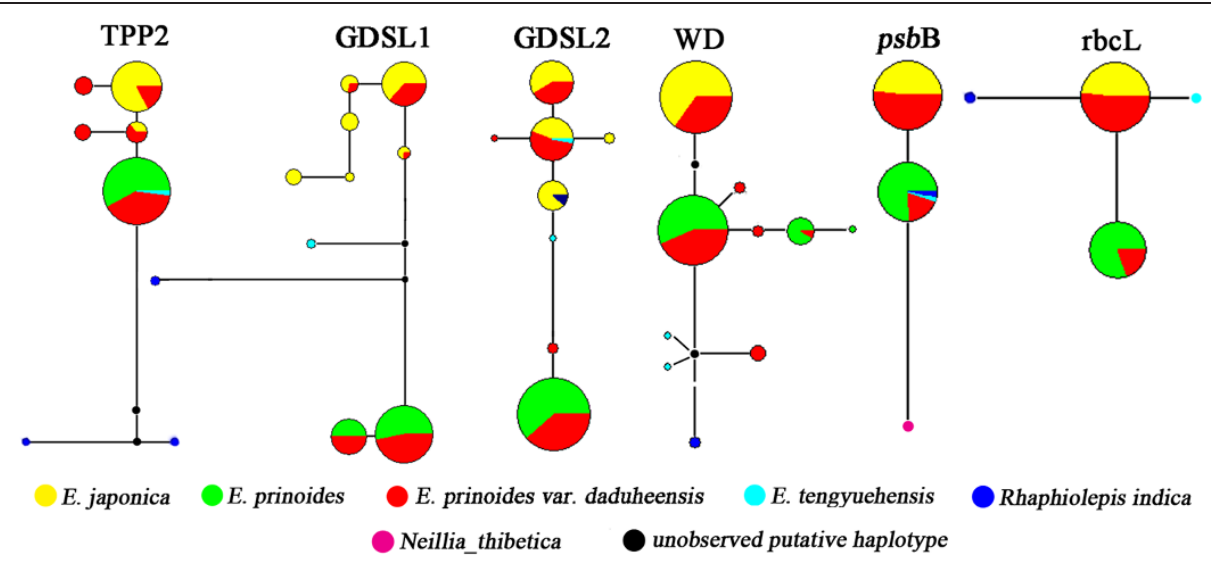

Figure 1 Haplotype networks of the six investigated genes for E. japonica, E. prinoides, and their putative hybrid. Mutational steps are shown by the length of the connecting lines, indels with more than one nucleotide were considered as one mutation, and node size is proportional to the number of haplotypes possessed by all the investigated individuals.

At the two chloroplast regions, J and P types were observed in 28 and 7 individuals of E. prinoides var. daduheensis, respectively. Although DP6 was observed with P type at all four nuclear genes, it exhibited a J type at the chloroplast regions. Of the 10 individuals detected with a $\mathrm{H}$ type at all four nuclear genes, J and $\mathrm{P}$ types were observed in 7 and 3 individuals, respectively (Table 2).

For the haplotype analysis, E. japonica harbored a higher level of diversity than E. prinoides at the genes TPP2, GDSL1 and GDSL2 (2, 6 and 4 haplotypes, respectively in E. japonica, and 1, 2 and 1 haplotypes, respectively in $E$. prinoides). This situation is reversed at the gene WD, where E. japonica had only one haplotype and E. prinoides had three. At the chloroplast regions, no within-species variation was observed. None of these haplotypes were shared by E. japonica and E. prinoides at all four nuclear genes and two chloroplast regions. For E. prinoides var. daduheensis, most haplotypes (18/25) were the same as those of E. japonica or E. prinoides (Figure 1). There were also seven haplotypes unique to E. prinoides var. daduheensis and only one mutational step existed between the six of them and the haplotypes of E. japonica or E. prinoides.

\section{Discussion}

\section{Molecular evidence for the hybrid origin of $E$. prinoides var. daduheensis}

The taxonomic status of E. prinoides var. daduheensis has been controversial. It was recognized as either a variety of E. prinoides [16], a natural hybrid between E. prinoides and E. japonica [17], or a variety of E. japonica [18]. However, due to very limited sampling, there has been no convincing conclusion regarding its status. In this study, we aimed to characterize its status by sequencing four nuclear genes and two chloroplast regions for sufficient samples of the three taxa of Eriobotrya in two locations. Our results showed that there were a few fixed nucleotide substitutions between E. japonica and E. prinoides in all four nuclear genes and two chloroplast regions, indicating that the two species are well separated. Most individuals of E. prinoides var. daduheensis (33 of 35 ) showed nucleotide additivity of E. japonica and $E$. prinoides in at least one nuclear gene, providing direct evidence that they are hybrids between E. japonica and E. prinoides. The remaining two individuals, DP6 and DP8, are also hybrids because DP6 is P type at all four nuclear genes and J type at the chloroplast regions and DP8 is P type at two nuclear genes and J type at the two other nuclear genes. In the ten individuals of $E$. prinoides var. daduheensis, nucleotide additivity of E. japonica and $E$. prinoides was observed at all of the four randomly selected nuclear genes, suggesting that they might be $F_{1}$ hybrids. Other individuals of E. prinoides var. daduheensis must be later-generation hybrids. Of the 10 putative $F_{1}$ hybrids, J and P types were observed in 7 and 3 individuals, respectively, at the two chloroplast loci, indicating that both species could serve as female parent. In this study, seven haplotypes from 3 nuclear genes were unique to E. prinoides var. daduheensis (Figure 1). These may be due to unsampled polymorphisms from the parental species, or new mutations in the hybrids.

Molecular analyses show that 9 of 21 individuals of typical $E$. prinoides var. daduheensis are likely $\mathrm{F}_{1}$ hybrids, while there is only one out of 14 individuals of atypical E. prinoides var. daduheensis. These results suggest that typical E. prinoides var. daduheensis contains many $\mathrm{F}_{1}$ hybrids, whereas most atypical E. prinoides var. daduheensis are later-generation hybrids.

The four nuclear genes developed from apple, which is a Pyrinae species distantly related to Eriobotrya, were also 
Table 2 Sequence type of the six investigated genes in each putative hybrid ${ }^{\mathrm{a}}$

\begin{tabular}{|c|c|c|c|c|c|c|}
\hline$I D^{b}$ & Location & TPP2 & GDSL1 & GDSL2 & WD & $p s b \mathrm{~B}+\mathrm{rbcL}$ \\
\hline D1 & Hanyuan & $\mathrm{H}$ & $P$ & $\mathrm{H}$ & $\mathrm{H}$ & J \\
\hline D2 & Hanyuan & $\mathrm{H}$ & $\mathrm{H}$ & $\mathrm{H}$ & $\mathrm{H}$ & J \\
\hline D3 & Hanyuan & $\mathrm{H}$ & $\mathrm{H}$ & $\mathrm{H}$ & $\mathrm{H}$ & P \\
\hline D4 & Hanyuan & J & $P$ & $\mathrm{H}$ & $\mathrm{H}$ & J \\
\hline D5 & Hanyuan & J & $\mathrm{H}$ & $\mathrm{H}$ & $\mathrm{H}$ & J \\
\hline D6 & Hanyuan & $\mathrm{H}$ & $\mathrm{H}$ & $\mathrm{H}$ & $\mathrm{H}$ & J \\
\hline D7 & Hanyuan & $\mathrm{H}$ & $\mathrm{H}$ & $\mathrm{H}$ & $\mathrm{H}$ & J \\
\hline D8 & Hanyuan & J & P & $\mathrm{H}$ & $P$ & J \\
\hline D9 & Hanyuan & P & P & $\mathrm{H}$ & $\mathrm{H}$ & P \\
\hline D10 & Hanyuan & P & $\mathrm{H}$ & J & $\mathrm{H}$ & P \\
\hline D11 & Hanyuan & $H$ & $\mathrm{H}$ & $H$ & $\mathrm{H}$ & $P$ \\
\hline D12 & Hanyuan & $\mathrm{H}$ & P & $\mathrm{H}$ & $\mathrm{H}$ & P \\
\hline D13 & Simian & $\mathrm{H}$ & P & $\mathrm{H}$ & $\mathrm{H}$ & J \\
\hline D14 & Simian & $\mathrm{H}$ & $P$ & $\mathrm{H}$ & P & J \\
\hline D15 & Simian & $\mathrm{H}$ & $\mathrm{H}$ & $\mathrm{H}$ & $\mathrm{H}$ & J \\
\hline D15 & Simian & $H$ & $H$ & $\mathrm{H}$ & $\mathrm{H}$ & J \\
\hline D17 & Simian & $\mathrm{H}$ & $P$ & $\mathrm{H}$ & $\mathrm{H}$ & J \\
\hline D18 & Simian & $\mathrm{H}$ & P & $\mathrm{H}$ & $\mathrm{H}$ & J \\
\hline D19 & Simian & $\mathrm{H}$ & P & $\mathrm{H}$ & $\mathrm{H}$ & J \\
\hline D20 & Simian & $\mathrm{H}$ & $\mathrm{H}$ & $\mathrm{H}$ & $\mathrm{H}$ & J \\
\hline D21 & Simian & $\mathrm{H}$ & $\mathrm{H}$ & $\mathrm{H}$ & $\mathrm{H}$ & J \\
\hline DP1 & Hanyuan & $\mathrm{H}$ & $P$ & $\mathrm{H}$ & $P$ & J \\
\hline DP2 & Hanyuan & $P$ & $P$ & $\mathrm{H}$ & $P$ & $P$ \\
\hline DP3 & Hanyuan & $\mathrm{H}$ & $\mathrm{H}$ & $\mathrm{H}$ & $\mathrm{H}$ & P \\
\hline DP4 & Simian & P & P & $\mathrm{H}$ & $\mathrm{H}$ & J \\
\hline DP5 & Simian & $\mathrm{H}$ & $P$ & $P$ & $P$ & J \\
\hline DP6 & Simian & $P$ & $P$ & $P$ & $P$ & J \\
\hline DP7 & Simian & $\mathrm{H}$ & $P$ & P & $P$ & J \\
\hline DP8 & Simian & P & J & J & $P$ & J \\
\hline DP9 & Simian & P & $P$ & $\mathrm{H}$ & P & J \\
\hline DJ1 & Simian & $\mathrm{H}$ & P & $\mathrm{H}$ & $\mathrm{H}$ & J \\
\hline DJ2 & Simian & $\mathrm{H}$ & J & $\mathrm{H}$ & J & J \\
\hline DJ3 & Simian & $P$ & $\mathrm{H}$ & $\mathrm{H}$ & $\mathrm{H}$ & J \\
\hline DJ4 & Simian & $\mathrm{H}$ & $\mathrm{H}$ & P & $\mathrm{H}$ & J \\
\hline DJ5 & Simian & $\mathrm{H}$ & P & $\mathrm{H}$ & $\mathrm{H}$ & J \\
\hline
\end{tabular}

${ }^{a}$ According to fixed nucleotide substitutions between $E$. japonica and $E$. prinoides, sequences are same with those of E. japonica are defined as type "J", sequences are same with those of E. prinoides are defined as type " $\mathrm{P}$ ", and sequences are the nucleotide additivity of both are defined as type " $\mathrm{H}$ ". ${ }^{\mathrm{b}}$ D1-21: individual identified as typical E. prinoides var. daduheensis; DP1-9: individual with characters between $E$. prinoides var. daduheensis and $E$. prinoides; DJ1-5: individual with characters between $E$. prinoides var. daduheensis and E. japonica.

successfully applied in Eriobotrya and Rhaphiolepis in this study, and other genera of Pyrinae, such as Cotoneaster and Sorbus (Chen et al. unpublished data). This indicates that the four nuclear genes can be widely applied as universal nuclear markers for hybrid identification and phylogenetic analyses in species of Pyrinae.

Factors contributing to the natural hybridization between E. japonica and E. prinoides

The geographic distribution, flower morphology, and blooming periods of E. japonica and E. prinoides may provide ample opportunities for hybridization between these species. The two species are found in Simian and Hanyuan, Sichuan, China [15] and are partially sympatric in habitat; however, E. japonica prefers higher elevations and $E$. prinoides prefers lower elevations. The flowering periods of E. japonica and E. prinoides also overlap: both species flowers from October to February [16]. During our field investigations in December, 2007, we found that E. japonica, E. prinoides and E. prinoides var. daduheensis were blooming at the same time. The overall flower morphology of the two species is quite similar, except for the size of inflorescence and the number of style [16], and bees in the autumn and passerine birds in the winter are shared pollinators for them [25]. In short, E. japonica and E. prinoides have ample opportunities to hybridize with each other naturally in places where they occur together.

\section{Consequences of hybridization between loquat and \\ E. prinoides}

In this study, 25 of the 35 investigated individuals were confirmed to be later-generation hybrids, suggesting that $F_{1}$ hybrids can backcross with parental species and introgression may take place. During our field investigations, hundreds of $E$. prinoides var. daduheensis individuals were found, so the potential for introgression is great. Although no signals of introgression were observed in the sampled individuals of either E. japonica or E. prinoides, the possibility cannot be excluded because only four nuclear genes and chloroplast DNA were analyzed. E. japonica and E. prinoides occupy differential altitude range with slight overlap. Differential adaptation might

Table 3 Morphological characters of E. japonica, $E$. prinoides and typical E. prinoides var. daduheensis

\begin{tabular}{llll}
\hline Character & E. japonica & E. prinoides & $\begin{array}{l}\text { E. prinoides } \\
\text { var. daduheensis }\end{array}$ \\
\hline Leaf margin & Serrate & Undulate & Serrate \\
Upper surface of leaf & Rugose & Smooth & Smooth \\
Leaf size $(\mathrm{cm})$ & $12-30 \times 5-10$ & $7-15 \times 3.5-7.5$ & $10-24 \times 4.5-9$ \\
Petiole length $(\mathrm{cm})$ & $0.2-0.8$ & $1.5-3$ & $1-2.5$ \\
Stipule shape & Subulate & Ovate & Subulate \\
Inflorescence & $10-20.5$ & $6-10$ & $8-12$ \\
length (cm) & & & $3-4$ \\
Number of styles & 5 & 2, rarely 3 & 3 \\
\hline
\end{tabular}


Table 4 Sample locations of E. japonica, E. prinoides, E. prinoides var. daduheensis and outgroups used in this study

\begin{tabular}{lllll}
\hline E. japoncina $(\mathrm{J})$, E. prinoides $(\mathbf{P})$, and E. prinoides var. Daduheensis $(\mathbf{H})$ \\
\hline & & J & P & H \\
\hline Shimian County, Sichuan, China & $29^{\circ} 14^{\prime} \mathrm{N}, 102^{\circ} 19^{\prime} \mathrm{E}$ & 13 & 13 & 20 \\
Hanyuan County, Sichuan, China & $29^{\circ} 17^{\prime} \mathrm{N}, 102^{\circ} 39^{\prime} \mathrm{E}$ & 13 & 15 & 15 \\
Other species used as outgroup & & & & \\
Gongshan, Yunnan, China & $27^{\circ} 43^{\prime} \mathrm{N}, 98^{\circ} 40^{\prime} \mathrm{E}$ & E. tengyueensis \\
Guangzhou, Guangdong, China & $23^{\circ} 6^{\prime} \mathrm{N}, 113^{\circ} 18^{\prime} \mathrm{E}$ & Rhaphiolepis indica
\end{tabular}

maintain species integrity of $E$. japonica and $E$. prinoides in the presence of hybridization and potential introgression.

Introgressive hybridization between E. japonica and E. prinoides may help to increase the genetic diversity of their wild populations, which might be advantageous for their long-term survival in the context of rapid global climate changes. Meanwhile, local people can use natural hybrid individuals to select new cultivars of loquat. Wild individuals of the two Eriobotrya species are widely used as rootstock to graft loquat cultivars, so many wild populations have been destroyed (Fan et al. personal observation). The current status of these Eriobotrya species calls for effective conservation.

\section{Conclusions}

Based on sequence data of four low-copy nuclear genes and two chloroplast regions, we provided convincing evidence for the hybrid origin of $E$. prinoides var. daduheensis, and found that most hybrid individuals could be later generation hybrids. Our study demonstrated a successful application of low-copy nuclear genes in the identification of hybrids in the subtribe Pyrinae, and primers developed in this study could be applied in other genera of Pyrinae.

\section{Methods}

\section{Plant sampling}

In December 2007 (when the three Eriobotrya taxa were blooming) and in April 2008 (when the fruits of these Eriobotrya taxa were ripening), we conducted field surveys of the three Eriobotrya taxa in Hanyuan and Simian, Sichuan, China. Based on their morphological characteristics [13,16,26] and our own observations, seven diagnostic morphological characteristics were used to identify E. japonica, E. prinoides and E. prinoides var. daduheensis (Table 3). At both sampling sites, only $E$. prinoides can be found at an elevation below $800 \mathrm{~m}$, whereas only E. japonica can be found at elevations above $1200 \mathrm{~m}$. At an elevation between 800-1200 m, all three taxa can be found. In addition, some individuals exhibit an intermediate morphology of E. prinoides var. daduheensis and either E. japonica or E. prinoides (We provisionally treated them as E. prinoides var. daduheensis). In this study, we sampled 28 individuals of $E$. prinoides below 800 m, 26 individuals of E. japonica above $1200 \mathrm{~m}$, and 35 individuals of E. prinoides var. daduheensis between 800 and $1200 \mathrm{~m}$ (including 21 individuals of typical E. prinoides var. daduheensis, 5 individuals with an intermediate morphology of E. japonica and E. prinoides var. daduheensis, and 9 individuals with an intermediate morphology of E. prinoides and E. prinoides var. daduheensis). In addition, one congeneric species (E. tengyuehensis) and one species of a closely related genus, Rhaphiolepis indica, were sampled and used as outgroups (Table 4). For the $p s b \mathrm{~B}$ gene, a sequence from Neillia thibetica (Rosaceae) was downloaded from NCBI website and set as outgroup (Accession number: JF317470). All of the leaves for DNA extraction were collected and stored in silica gel in zip-lock plastic

Table 5 Primers of the four nuclear genes designed from a coding sequence database of Malus $\times$ domestica

\begin{tabular}{|c|c|c|c|}
\hline Locus & Primer sequences $\left(5^{\prime}-3^{\prime}\right)$ & The aligned length (bp) & ID for apple coding sequence \\
\hline \multirow[t]{2}{*}{ TPP2 } & F: GCTGGTTTTGTTCATCGA & 389 & MDP0000193152 \\
\hline & R: ACCGCTCAGAAACAGGCT & & \\
\hline \multirow[t]{2}{*}{ GDSL1 } & F: GTCTTCCAAGGCTTCGTT & 661 & MDP0000137339 \\
\hline & R: ACAATTCCCGTTCCACAG & & \\
\hline \multirow[t]{2}{*}{ GDSL2 } & F: identical with GDSL1 & 591 & identical with GDSL1 \\
\hline & R: identical with GDSL1 & & \\
\hline \multirow[t]{2}{*}{ WD } & F: GTTCCTCTATCATCACCAGTT & 736 & MDP0000283138 \\
\hline & R: ACCAGTGCCAAGTCTATTC & & \\
\hline \multirow[t]{2}{*}{$\mathrm{rbcL}$} & 724F: GCTACTGCAGGTACATG & 754 & \\
\hline & 1352R: CTTCACAAGCAGCAGCTAGTTC & & \\
\hline \multirow[t]{2}{*}{$p s b B$} & F:AACGAGTGGGACCAAATA & 317 & \\
\hline & R:TTTCTATTCAGGGGTGGC & & \\
\hline
\end{tabular}


bags until use. Voucher specimens were deposited in the Herbarium of Sun Yat-sen University (SYS).

\section{DNA extraction, primer design, $\mathrm{PCR}$ and sequencing}

Genomic DNA was isolated using the CTAB method [27]. Based on them, specific EPIC primers were designed using Primer Premier 6.0 (PREMIER Biosoft International, Palo Alto, CA, USA). These cDNAs encode tripeptidyl peptidase II (TPP2), GDSL esterase/lipase APG-like proteins (GDSL), and WD repeat-containing protein (WD). One bright band was amplified for the TPP2 and WD primers, and two bright bands were amplified using the GDSL primers (we designated them as GDSL1 and GDSL2). The chloroplast $r b c \mathrm{~L}$ region was amplified using universal primers [28], while a partial $p s b \mathrm{~B}$ region was amplified using specific primers based on the sequences of some individuals of Eriobotrya, which were obtained from the universal primers $p s b \mathrm{~B} 1-\mathrm{F}$ and $p s b \mathrm{~B} 2-\mathrm{R}$ [29]. All of the primer sequences are listed in Table 5.

PCR amplifications were performed in $20 \mu \mathrm{L}$ reaction volumes, containing $25 \mathrm{ng}$ of genomic DNA, $2 \mu \mathrm{L}$ of $10 \times$ buffer (with $\mathrm{Mg}^{2+}$ ), $0.25 \mathrm{mM}$ of dNTPs, $0.2 \mu \mathrm{M}$ of each primer, and $1 \mathrm{U}$ of Easy-Taq DNA polymerase (TransGen Biotech Co., Ltd, Beijing, China). The PCR reactions were conducted with the following conditions: initial denaturing at $94^{\circ} \mathrm{C}$ for $2.5 \mathrm{~min}$, followed by $35 \mathrm{cy}-$ cles of $94^{\circ} \mathrm{C}$ for $30 \mathrm{~s}$, a corresponding annealing temperature $\left(50^{\circ} \mathrm{C}\right.$ for $\mathrm{TPP} 2, \mathrm{WD}$, and $r b c \mathrm{~L}$, and $55^{\circ} \mathrm{C}$ for GDSL and $p s b \mathrm{~B}$ ) for $30 \mathrm{~s}, 72^{\circ} \mathrm{C}$ for $1 \mathrm{~min}$, and a final extension at $72^{\circ} \mathrm{C}$ for $5 \mathrm{~min}$. The PCR products were purified by electrophoresis with a 1.2\% agarose gel followed by the use of a Pearl Gel Extraction Kit (Pearl Biotech, Guangzhou, China). Following purification, they were sequenced on an ABI 3730 DNA automated sequencer with the BigDye Terminator Cycle Sequencing Ready Reaction Kit (Applied Biosystems, Foster City, CA). All sequences were deposited in GenBank under accession numbers KF699531-KF699842, KJ735102-KJ735383, and KM246943-KM246944.

\section{Sequences analysis}

The sequences were assembled and edited with SeqMan ${ }^{\mathrm{Tx}}$ II (DNASTAR, Inc., Madison, WI), and then subjected to a BLASTN search against the genome sequence of apple (http://www.rosaceae.org/species/malus/malus_x_ domestica/genome_v1.0) to determine their possible copy number in the genome, setting an E-value cut-off of $1 \mathrm{e}^{-6}$ and a minimum score of 100 bits. The results showed that no more than three hits were obtained for each of the four investigated genes, indicating that they are low-copy ones in the genome. For each of the four nuclear genes, we also designed 2-3 pairs of primers anchoring different locations (data not shown). Sequencing for their PCR products produced identical sequences at the target regions, supporting that they are very likely orthologous in Eriobotrya. Polymorphisms at variable sites were identified as superimposed nucleotide additivity patterns from chromatograms of direct sequencing [30], and indels were identified by reading the sequence chromatogram from both sides. The haplotype inference of the four nuclear genes was implemented with PHASE v2.1 [31,32]. The haplotype network was constructed for each gene using Network 4.6.1.2 (www.fluxus-engineering.com) with the median-joining algorithm [33].

\section{Competing interests}

The authors declare that they have no competing interests.

\section{Authors' contributions}

The experimental design was conceived by WL and RZ. All samples were collected by WG and $\mathrm{HJ}$, the experiments were performed by QF, SC and $\mathrm{ML}$, and data was analyzed by QF, SC. This paper was written by QF, SC, WW, RZ and WL. All authors read and approved the final manuscript.

\section{Acknowledgements}

This work was supported by the National Natural Science Foundation of China (31100159, 31170202, 31170213 and 31200175), the Doctoral Foundation of Ministry of Education of China (20110171110032) and the Fundamental Research Funds for the Central Universities (13lgpy07).

\section{Author details}

'Guangdong Key Laboratory of Plant Resources, Key Laboratory of Biodiversity Dynamics and Conservation of Guangdong Higher Education Institutes, School of Life Sciences, Sun Yat-sen University, Guangzhou 510275, China. ${ }^{2}$ Department of Horticulture and Landscape Architecture, Zhongkai University of Agriculture and Engineering, Guangzhou 510225, China. ${ }^{3}$ South China Botanical Garden, Chinese Academy of Science, Guangzhou 510650, China.

Received: 23 June 2014 Accepted: 3 October 2014

Published online: 10 October 2014

\section{References}

1. Mallet J: Hybrid speciation. Nature 2007, 446:279-283.

2. Soltis PS, Soltis DE: The role of hybridization in plant speciation. Annu Rev Plant Biol 2009, 60:561-588.

3. Hegarty MJ, Hiscock SJ: Hybrid speciation in plants: new insights from molecular studies. New Phytol 2005, 165:411-423.

4. Campbell CS, Evans RC, Morgan DR, Dickinson TA, Arsenault MP: Phylogeny of subtribe Pyrinae (formerly the Maloideae, Rosaceae): limited resolution of a complex evolutionary history. Plant Syst Evol 2007, 266:119-145.

5. Robertson KR, Phipps JB, Rohrer JR, Smith PG: A synopsis of genera of the Maloideae (Rosaceae). Syst Bot 1991, 16:376-394.

6. Campbell CS, Wright WA: Apomixis, hybridization, and taxonomic complexity in eastern North American Amelanchier. Folia Geobot Phytotax 1996, 31:345-354.

7. Byatt J: Hybridization between Crataegus monogyna Jacq. and C. laevigata (Poiret) DC. in south-eastern England. Walsonia 1975, 10:253-264.

8. Gosler AG: Introgressive hybridization between Crataegus monogyna Jacq. and C. laevigata (Poiret) DC. in the Upper Thames Valley, England. Watsonia 1990, 18:49-62.

9. Phipps JB: A review of hybridization in north American hawthorns another look at "the Crataegus problem". Ann Mo Bot Grad 2005, 92:113-126.

10. Robertson A, Rich TC, Allen AM, Houston L, Roberts C, Bridle JR, Harris SA, Hiscock SJ: Hybridization and polyploidy as drivers of continuing evolution and speciation in Sorbus. Mol Ecol 2010, 19:1675-1690.

11. Ludwig S, Robertson A, Rich TC, Djordjevic M, Cerovic R, Houston L, Harris SA, Hiscock SJ: Breeding systems, hybridization and continuing evolution in Avon Gorge Sorbus. Ann Bot 2013, 111:563-575. 
12. Mabberley DJ: The Plant-Book: A Portable Dictionary of the Vascular Plants. 2nd edition. New York, USA: Cambridge University Press; 1997.

13. Gu CZ, Spongberg SA: Eriobotrya. In Flora of China. Volume 9. Edited by Wu CY, Raven PH, Hong DY. St. Louris: Science Press, Beijing and Missouri Botanical Garden Press; 2003:140-143.

14. Qiu WL, Zhang HZ: Fruit Flora of China (Longan and Loquat). Beijing, China: China Forestry Press; 1996.

15. Lin $\mathrm{SQ}$, Yang $\mathrm{XH}$, Liu CM, Hu YL, He YH, Hu GB, Zhang HL, He XL, Liu YX, Liu ZL: Natural geographical distribution of genus Eriobotrya plants in China. Acta Horti Sin 2004, 31:569-573.

16. Zhang HZ, Peng S, Cai LH, Fang DQ: The germplasm resources of the genus Eriobotrya with special reference on the origin of E. japonica Lindl. Acta Horti Sin 1990, 17:5-12.

17. Tang B: A study of the sibship among Eriobotrya japonica Lindl, $E$. prinoides Rehd \& wils. var. daduheensis H. Z. Zhang and E. prinoides Rehd. \& Wils. Journal of Chongqing Teachers College (Natural Science Edition) 1997, 14:18-25.

18. Liang GL, Ren ZC, Yan Y, Li XL, Jiang NG: Karyotype variation and evolution of genus Eriobotrya in Sichan. Adv Chromosome Sci 2001, 1:311-316.

19. Zhang R, Liu T, Wu W, Li Y, Chao L, Huang L, Huang Y, Shi S, Zhou R: Molecular evidence for natural hybridization in the mangrove fern genus Acrostichum. BMC Plant Biol 2013, 13:74.

20. Wu W, Zhou R, Huang Y, Boufford DE, Shi S: Molecular evidence for natural intergeneric hybridization between Liquidambar and Altingia. J Plant Res 2010, 123:231-239.

21. Zha HG, Milne Rl, Sun H: Asymmetric hybridization in Rhododendron agastum: a hybrid taxon comprising mainly $\mathrm{F}_{1} \mathrm{~s}$ in Yunnan, China. Ann Bot 2010, 105:89-100.

22. Velasco R, Zharkikh A, Affourtit J, Dhingra A, Cestaro A, Kalyanaraman A, Fontana P, Bhatnagar SK, Troggio M, Pruss D, Salvi S, Pindo M, Baldi P, Castelletti S, Cavaiuolo M, Coppola G, Costa F, Cova V, Dal Ri A, Goremykin V, Komjanc M, Longhi S, Magnago P, Malacarne G, Malnoy M, Micheletti D, Moretto M, Perazzolli M, Si-Ammour A, Vezzulli S, et al: The genome of the domesticated apple (Malusx domestica Borkh.). Nat Genet 2010, 42:833-839.

23. Thomson RC, Wang IJ, Johnson JR: Genome-enabled development of DNA markers for ecology, evolution and conservation. Mol Ecol 2010, 19:2184-2195

24. Zhou R, Zeng K, Wu W, Chen X, Yang Z, Shi S, Wu Cl: Population genetics of speciation in nonmodel organisms: I. Ancestral polymorphism in mangroves. Mol Biol Evol 2007, 24:2746-2754.

25. Fang Q, Chen YZ, Huang SQ: Generalist passerine pollination of a winter-flowering fruit tree in central China. Ann Bot 2012, 109:379-384.

26. Kuan KC, Yü TT: Eriobotrya. In Rosaceae (1) Flora Reipublicae Popularis Sinicae. Volume 36. Edited by Yü TT. Beijing: Science Press; 1974:260-275.

27. Doyle JJ, Doyle JL: A rapid DNA isolation procedure from small quantities of fresh leaf tissues. Phytochem Bull 1987, 19:11-15.

28. Fay MF, Swensen SM, Chase MW: Taxonomic affinities of Medusagyne oppositifolia (Medusagynaceae). Kew Bull 1997, 52:111-120.

29. Heinze B: A database of PCR primers for the chloroplast genomes of higher plants. Plant Meth 2007, 3:4.

30. Whittall J, Liston A, Gisler S, Meinke RJ: Detecting nucleotide additivity from direct sequences is a SNAP: an example from Sidalcea (Malvaceae). Plant Biol 2000, 2:211-217.

31. Stephens M, Smith NJ, Donnelly P: A new statistical method for haplotype reconstruction from population data. Am J Hum Genet 2001, 68:978-989.

32. Stephens $M$, Scheet $P$ : Accounting for decay of linkage disequilibrium in haplotype inference and missing-data imputation. Am J Hum Genet 2005, 76:449-462.

33. Bandelt HJ, Forster $P$, Rohl A: Median-joining networks for inferring intraspecific phylogenies. Mol Biol Evol 1999, 16:37-48.

doi:10.1186/s12870-014-0275-6

Cite this article as: Fan et al:: Molecular evidence for natural hybridization between wild loquat (Eriobotrya japonica) and its relative E. prinoides. BMC Plant Biology 2014 14:275.

\section{Submit your next manuscript to BioMed Central and take full advantage of:}

- Convenient online submission

- Thorough peer review

- No space constraints or color figure charges

- Immediate publication on acceptance

- Inclusion in PubMed, CAS, Scopus and Google Scholar

- Research which is freely available for redistribution

Submit your manuscript at www.biomedcentral.com/submit
Biomed Central 